\title{
Is Pairing with a Relative Heritable? Estimating Female and Male Genetic Contributions to the Degree of Biparental Inbreeding in Song Sparrows (Melospiza melodia)
}

\author{
Matthew E. Wolak ${ }^{\star}$ and Jane M. Reid ${ }^{\dagger}$ \\ Institute of Biological and Environmental Sciences, School of Biological Sciences, University of Aberdeen, Aberdeen, United Kingdom \\ Submitted March 21, 2015; Accepted December 9, 2015; Electronically published April 18, 2016 \\ Online enhancements: appendixes, supplemental material. Dryad data: http://dx.doi.org/10.5061/dryad.70ng4.
}

\begin{abstract}
AвstRACt: The degree of inbreeding expressed within populations can profoundly shape evolutionary dynamics. The degree to which individuals inbreed is frequently assumed to evolve in response to selection, for example, resulting from inbreeding depression. Such evolutionary responses require additive genetic variance $\left(V_{\mathrm{A}}\right)$ in the degree to which individuals inbreed. However, the magnitude of $V_{\mathrm{A}}$ in the degree of biparental inbreeding has never been estimated. We devised a quantitative genetic model to estimate sex-specific $V_{\mathrm{A}}$ in the degree to which individuals inbreed while accounting for effects of individuals' own coefficients of inbreeding and genetic effects stemming from immigration. We applied this model to the degree of inbreeding expressed through social pairing in free-living song sparrows (Melospiza melodia). Estimates of $V_{\mathrm{A}}$ for both sexes appreciably exceeded 0 and the cross-sex genetic covariance was strongly positive, creating substantial total $V_{\mathrm{A}}$ in the degree of inbreeding. Our analyses also revealed inbreeding depression in the degree of inbreeding, such that more inbred individuals paired with closer relatives, and immigrant effects, such that individuals with greater genomic contributions from immigrants paired with more distant relatives. We thereby demonstrate that the degree of biparental inbreeding can show substantial $V_{\mathrm{A}}$ in nature and might consequently evolve in response to selection.

Keywords: animal model, genetic groups, inbreeding strategy, kinship, mating system evolution, quantitative genetics.
\end{abstract}

\section{Introduction}

Inbreeding, defined as mating between individuals that share homologous alleles identical by descent, is widely expected to profoundly influence the evolution of mating systems (Charlesworth and Charlesworth 1987), dispersal (Greenwood and Harvey 1982), and the maintenance of genetic variation (Wright 1969) and is therefore fundamental to ecological and evolutionary dynamics (Darwin 1876;

\footnotetext{
* Corresponding author; e-mail: matthew.wolak@abdn.ac.uk.

† ORCID: Wolak, http://orcid.org/0000-0002-7962-0071.

Am. Nat. 2016. Vol. 187, pp. 736-752. (C) 2016 by The University of Chicago. 0003-0147/2016/18706-56154\$15.00. All rights reserved.

DOI: $10.1086 / 686198$
}

Keller and Waller 2002; Charlesworth 2006). Specifically, offspring produced by parents that inbreed commonly experience reduced fitness (i.e., inbreeding depression), potentially driving the evolution of mechanisms that facilitate inbreeding avoidance or outcrossing (Charlesworth and Charlesworth 1987; Keller and Waller 2002; Szulkin et al. 2013). Conversely, inbreeding can increase an individual's inclusive fitness (Lehmann and Perrin 2003; Kokko and Ots 2006), maintain coadapted gene complexes (Templeton 1986; Pusey and Wolf 1996; Lynch and Walsh 1998, p. 223), facilitate purging of mutation load (Crow 1970; Crnokrak and Barrett 2002), and ensure fertilization when mates are scarce (Baker 1955; Lloyd 1979). Mechanisms that facilitate increased inbreeding or selfing might consequently evolve. Furthermore, different patterns of reproductive investment by females and males imply that producing inbred offspring can have sex-specific fitness consequences, creating sexually antagonistic selection on the degree to which individuals inbreed (Waser et al. 1986; Pizzari et al. 2004; Kokko and Ots 2006; Parker 2006; Szulkin et al. 2013; Duthie and Reid 2015; Reid et al. 2015a). A major objective in evolutionary ecology is therefore to understand how the degree to which individuals inbreed might evolve given multiple potentially conflicting components of sex-specific selection on inbreeding, culminating in increased or reduced biparental inbreeding or selfing (Goodwillie et al. 2005; Szulkin et al. 2013). Achieving this objective requires quantification of the key parameters that underlie evolutionary changes in the degree to which individuals inbreed.

In general, the expectation that any quantitative trait will evolve in response to selection requires that there is an additive genetic basis to phenotypic variation expressed within a population, such that the trait's narrow-sense heritability exceeds 0 (Falconer and Mackay 1996; Lynch and Walsh 1998). Therefore, the proposition that a population's mean degree of biparental inbreeding will evolve in response to negative, positive, or sexually antagonistic selection requires 
additive genetic variation $\left(V_{\mathrm{A}}\right)$ in the degrees to which females and males inbreed. However, no studies of either animals or plants have explicitly estimated $V_{\mathrm{A}}$ and tested this fundamental assumption underlying any hypothesis of adaptive biparental inbreeding, even though the degree of inbreeding commonly varies among individuals within free-living populations and therefore constitutes a measurable quantitative trait (e.g., Jamieson et al. 2009; RiouxPaquette et al. 2010; Billing et al. 2012; Robinson et al. 2012; Reid et al. 2015a, 2015b).

The degree of biparental inbreeding is a joint trait that results from mating between a female and male and cannot be expressed by either sex in isolation. Additive genetic variance in the degree of inbreeding is therefore most appropriately estimated by treating the observable phenotype of kinship between a mated female and male as an emergent trait of the pair rather than by assigning the phenotype entirely to one sex or the other a priori. In general, emergent traits are phenotypes that are jointly expressed by groups of two or more individuals rather than entirely expressed by any one individual alone. In a quantitative genetic context, each individual contributes genetic and environmental effects to the group phenotype, and across a population the variance among individuals in these effects constitutes part of the population-wide variance in emergent trait phenotypes (Bijma 2011, 2014). Specifically, female and male additive genetic variances underlying inbreeding $\left(V_{\mathrm{A} \text {-female }}\right.$ and $\left.V_{\mathrm{A} \text {-male }}\right)$ and the cross-sex covariance in additive genetic effects $\left(\mathrm{COV}_{\mathrm{A} \text {-female,male }}\right)$ can be estimated using quantitative genetic models that explicitly account for genetic and environmental effects of both interacting individuals (as implemented for other emergent traits; e.g., Brommer and Rattiste 2008; Hall et al. 2013; Reid et al. $2014 a)$. The total additive genetic variance $\left(V_{\mathrm{A}-\mathrm{TOT}}\right)$ in the degree of inbreeding provides a measure of a population's potential to respond to selection and is a function of the estimated $V_{\text {A-female, }} V_{\text {A-male, }}$ and $\mathrm{COV}_{\text {A-femalemale }}$ (Bijma et al. 2007a, 2007b; Bijma 2011, 2014). Positive or negative $\mathrm{COV}_{\text {A-femalemale }}$ would imply that additive effects of alleles carried by females and males are associated with congruent or opposing effects on the degree of inbreeding by their male and female relatives, respectively. Evolutionary changes in the mean degree to which individuals inbreed might then be more or less rapid - or even proceed in the opposite direction - than predicted if genetic variation and selection on females and males were considered independently (e.g., Griffing 1967; Bijma et al. 2007b). The sex through which selection could potentially drive more rapid evolution of the degree of biparental inbreeding can then be identified as that which contributes more to $V_{\text {A-тот. Joint estimation }}$ of $V_{\text {A-female, }}, V_{\mathrm{A} \text {-male, }}$ and $\mathrm{COV}_{\mathrm{A} \text {-female,male }}$ in the degree of inbreeding is therefore prerequisite to inference or prediction regarding ongoing evolution of biparental inbreeding, espe- cially given sexually antagonistic selection on biparental inbreeding (as is widely predicted; Pizzari et al. 2004; Parker 2006; Szulkin et al. 2013).

Ideally, quantitative genetic (co)variances underlying mating traits such as the degree of inbreeding need to be estimated in wild populations experiencing natural variation in mate choice, inbreeding, and kinship. This is because strict quantitative genetic breeding designs used in experimental populations may impose artificial selection and inbreeding (Ala-Honkola et al. 2011) and will inevitably constrain mating interactions, variance in fitness, and dispersal that could cause variation in inbreeding and kinship (Fuller and Hahn 1976; Boake 1989; Moore et al. 1997). Such breeding experiments might consequently alter genetic (co)variances that underpin ongoing evolution of inbreeding in nature (e.g., Kokko et al. 2006; Reid 2014). Quantitative genetic parameters can now be estimated from complex pedigree structures arising from natural mating systems (Kruuk 2004; Charmantier et al. 2014). However, there are two particular ways in which variation in inbreeding and kinship arising in natural populations, due to combinations of mate choice, dispersal, and variation in fitness, complicates estimation of additive genetic (co)variances underlying the degree of inbreeding.

First, inbreeding changes genotype frequencies and, in the presence of directional dominance, alters the population mean phenotype in the direction of recessive allelic values (i.e., inbreeding depression; Falconer and Mackay 1996, pp. 249, 264). Thus, offspring resulting from matings between relatives can show inbreeding depression in mating system traits (e.g., Aspi 2000; Reid et al. 2005; AlaHonkola et al. 2009; Bolund et al. 2010; Losdat et al. 2014) and potentially in the degree of inbreeding itself (Reid et al. 2006). In other words, being inbred might affect the degree to which an individual inbreeds (supplementary material A). Models aiming to estimate additive genetic (co)variances in the degree of inbreeding - or in any phenotypic traits in populations where inbreeding occursshould therefore simultaneously estimate inbreeding depression to minimize bias in estimates of quantitative genetic parameters (Kennedy et al. 1988; de Boer and van Arendonk 1992; Shaw et al. 1998; Reid and Keller 2010; Wolak and Keller 2014).

Second, dispersal among populations or demes can reduce the probability that dispersing individuals (and their mates) will inbreed without need for explicit mate choice based on kinship among subsequently available mates, even if dispersal did not evolve primarily due to selection for inbreeding avoidance (Moore and Ali 1984; Pusey and Wolf 1996; Lehmann and Perrin 2003; Szulkin et al. 2013). Furthermore, the existence of variation in dispersal, such that some individuals remain resident in their natal populations or demes while others disperse, might cause intergenera- 
tional covariances in the degree of biparental inbreeding. Such covariances could arise because both dispersing individuals and their immediate descendants that remain in the recipient population will be relatively unrelated to existing residents, while existing residents and their immediate descendants might be more closely related to other residents (Cavalli-Sforza et al. 1966; Jacquard 1974, pp. 197-201). Models aiming to estimate additive genetic (co)variances in the degree of inbreeding occurring within a focal study population must therefore account for (co)variation in kinship and inbreeding stemming from current and ancestral dispersal into the focal population (i.e., from the varying proportions of individuals' genomes that stem from immigrants). More generally, failure to appropriately model genetic effects of immigrants can bias quantitative genetic analyses of any trait if immigrants' source populations contain different average genetic effects underlying focal traits from the study population into which they immigrate (Westell et al. 1988; Van Vleck 1990; Postma 2006). Such bias can be eliminated by modeling genetic groups, as implemented in agricultural breeding science (Quaas 1988; Westell et al. 1988). In addition to eliminating bias, incorporating immigrant genetic groups also provides biologically interesting estimates of the relative genetic values for local inbreeding of residents versus immigrants and, hence, estimates the genetic value of among-deme dispersal in terms of subsequent inbreeding. However, such genetic group models have not been utilized in evolutionary ecology. Since many wild study populations receive immigrants, analyses of any trait in any such wild populations could benefit by estimating the genetic differences between immigrants and residents while simultaneously reducing bias in estimates of additive genetic effects and their (co)variances (Hadfield et al. 2010).

We used long-term pairing and pedigree data from freeliving song sparrows (Melospiza melodia) to estimate sexspecific additive genetic variances $\left(V_{\mathrm{A} \text {-female }}\right.$ and $\left.V_{\mathrm{A} \text {-male }}\right)$ and cross-sex genetic covariance $\left(\mathrm{COV}_{\mathrm{A} \text {-female,male }}\right)$ in the degree of inbreeding arising through the formation of socially persistent breeding pairs. We thereby test the hypothesis that the degree of biparental inbreeding expressed through such pairing shows nonzero additive genetic variance and could consequently respond to selection. Specifically, we treat the coefficient of kinship between socially paired mates as an emergent trait in a quantitative genetic animal model. We simultaneously model the relationships with each individual's own coefficient of inbreeding, thereby quantifying sex-specific inbreeding depression in the degree to which individuals inbreed. Furthermore, we model genetic group effects, thereby estimating the difference in genetic value for inbreeding between residents and immigrants and illustrating the implementation and value of such genetic group models in evolutionary ecology.

\section{Methods \\ Study Population and Pairing}

A resident population of song sparrows on Mandarte Island, British Columbia, Canada, has been intensively studied since 1975 (Smith et al. 2006) and recently averaged 32.2 (SD: 14.5) breeding pairs per year. This population has proved valuable for quantifying the occurrence and fitness consequences of inbreeding (Keller 1998; Keller and Arcese 1998; Reid et al. 2006, 2008, 2014a, 2015a, 2015b, 2015c). Mandarte's song sparrows are primarily socially monogamous; females and males form discrete, socially persistent breeding pairs and cooperate to defend breeding territories and rear offspring (Arcese et al. 2002; Janssen et al. 2008). While there is frequent extrapair reproduction, most offspring $(\sim 72 \%)$ are sired by a female's socially paired male, and such within-pair offspring account for most variance in total reproductive success (Sardell et al. 2010; Lebigre et al. 2012; see also Webster et al. 1995). Thus, the degree to which an individual pairs with a relative-and, hence, produces inbred within-pair offspring - can substantially affect fitness. While extrapair paternity can be comprehensively observed (Sardell et al. 2010), extrapair matings cannot. Observed extrapair paternity cannot be used as a proxy for the degree to which extrapair mates are related because paternity confounds kinship between mates with postcopulatory sexual selection and early offspring mortality following inbreeding (Reid et al. 2015b). Furthermore, there is scant evidence that female song sparrows actively alter their kinship with the sire of their offspring through nonrandom extrapair reproduction (Reid et al. 2015b, 2015c). Current analyses therefore focus on the degree to which individuals formed socially persistent breeding pairs with relatives as one key mating system trait.

Each year, all nests were found and all nestlings surviving to $\sim 6$ days posthatch were marked with unique combinations of metal and colored plastic bands, allowing individuals to be identified by field observation. All 35 immigrants that settled on Mandarte since 1975 (average: 0.92 year $^{-1} ; 26$ females and 9 males) were banded soon after arriving (e.g., Marr et al. 2002). This immigration rate is sufficient to maintain allelic diversity (Keller et al. 2001) and prevent inbreeding from rapidly accumulating. All socially persistent pairings of females and males that formed and bred (i.e., produced at least one clutch) were identified by frequent systematic observation of reproductive behaviors (e.g., territory defense, incubation, chick provisioning; Smith et al. 2006). Individuals of both sexes can breed up to three times per season from age 1 year and have median reproductive life spans of 2 years (maximum: 8 years; Smith et al. 2006). Social pairs often remained together across multiple breeding attempts within and across years (Keller and Arcese 1998). However, mortality and divorce meant that new social pairings regularly form both be- 
tween years and between breeding attempts within years (Smith et al. 2006; Reid et al. 2015c).

\section{Pedigree, Kinship, and Immigrants}

Since $1993,>99 \%$ of banded chicks and adults underwent blood sampling and genotyping at 160 polymorphic microsatellite loci, allowing genetic parentage to be assigned with extremely high confidence (Sardell et al. 2010; Reid et al. 2014b, 2015b; Nietlisbach et al. 2015). Furthermore, 37 chicks that hatched during 1991 and 1992 and bred subsequently were also genotyped, and their parentage was verified. Overall, $28 \%$ of chicks were assigned to extrapair sires (Sardell et al. 2010; Reid et al. 2014a, 2014b). We first compiled a pedigree based on field observations of social pairings and parental behavior from 1975 to 2014 and then corrected this pedigree for extrapair paternity using all available genetic parentage data (Reid et al. 2014b, 2015b, $2015 c$ ). The pedigree includes all individuals that bred on Mandarte since 1975, but parents of some chicks fledged in 1980 are unknown due to reduced fieldwork (Keller 1998).

We used the pedigree to estimate the degree to which individuals paired with a relative as the pairwise coefficient of kinship between socially paired mates $\left(k_{\mathrm{SOC}}\right)$, defined as the probability that homologous alleles sampled from two paired individuals will be identical by descent relative to the pedigree base population (Falconer and Mackay 1996, p. 85). Values of $k_{\mathrm{SOC}}=0.25,0.125$, and 0.0625 refer to pairings among outbred first-, second-, and third-order relatives, respectively. We also used the pedigree to estimate each individual's own coefficient of inbreeding $(f)$, defined as the probability that two homologous alleles within an individual are identical by descent relative to the base population (Falconer and Mackay 1996, p. 84). For within-pair offspring, $f$ equals $k_{\mathrm{SOC}}$ between an individual's socially paired parents.

We defined the primary base population as all adult song sparrows alive on Mandarte in 1975, thereby assuming that these individuals are all unrelated (app. B; apps. A, B are available online). We defined immigrants as unrelated to the resident Mandarte population at the time of arrival and to each other (Reid et al. 2006). This assumption is reasonable because Mandarte lies within a large song sparrow metapopulation, with numerous adjacent populations from which immigrants could have originated, many with large population sizes (Marr et al. 2002; Smith et al. 2006). Furthermore, microsatellite genotypes indicate that immigrants are not closely related to Mandarte residents (Keller et al. 2001; Marr et al. 2002). Thus, we defined $k_{\text {soc }}$ between an immigrant and its first mate as 0 and defined resulting offspring as outbred ( $f=0$; Reid et al. 2006, 2014a, 2014b). However, $k_{\mathrm{SOC}}$ can exceed 0 in subsequent matings if an immigrant paired with its own offspring or grandoffspring.
We restricted the phenotypic data for $k_{\mathrm{soc}}$ to the first observation of each unique social pair for which the parents of both the female and the male were verified through genotyping or were unknown because one paired individual was an immigrant (no pairs comprised two immigrants), thereby eliminating parental pedigree error. Further restriction to pairs where grandparents of both mates were genetically verified or unknown due to immigration excluded only 20 pairs ( $\sim 4 \%$ of the full data set) and did not qualitatively change the results. We did not treat $k_{\mathrm{SOC}}$ as a repeated measure across all years or breeding attempts for which a given pair persisted because there is zero variance in $k_{\mathrm{SOC}}$ within a pairing.

\section{Univariate Animal Model of $\mathrm{k}_{s o c}$ as an Emergent Trait}

We partitioned genetic and nongenetic components of variation in $k_{\mathrm{SOC}}$ using a univariate animal model (Henderson 1973; Lynch and Walsh 1998; Kruuk 2004), with $k_{\text {soc }}$ modeled as an emergent trait that is jointly expressed by socially paired females and males. In addition to an overall mean, we modeled fixed effects (i.e., regressions) of $k_{\text {soc }}$ on each female's and male's own coefficient of inbreeding $(f)$ and genetic group coefficient (GG; expected proportion of each individual's genome derived from immigrants). The regressions on female and male $f$ estimated inbreeding depression in the degree to which individuals pair with a relative (Reid and Keller 2010). Immigrants were excluded from these regressions because their $f$ values are undefined relative to the Mandarte pedigree base population. However, offspring of immigrants, which are defined as outbred, were included. The regressions on female and male GG values accounted for the differences in mean breeding value for $k_{\mathrm{SOC}}$ of immigrant and resident base populations (see "Genetic Groups" below).

We estimated female and male additive genetic variance ( $V_{\mathrm{A} \text {-female }}$ and $\left.V_{\mathrm{A} \text {-male }}\right)$, permanent individual variance $\left(V_{\mathrm{PI}}\right.$ female and $V_{\mathrm{PI}-\mathrm{male}}$, assumed to encompass repeatable environmental variation and components of nonadditive genetic variation), variance associated with the year of pair formation $\left(V_{\mathrm{YR}}\right)$, and residual variance $\left(V_{\mathrm{R}}\right)$. The linear mixed effects model for the vector of observations of $k_{\mathrm{SOC}}$ (y) in general matrix notation is (Bijma et al. 2007a):

$$
\begin{aligned}
\mathbf{y} & =\mathbf{X} \boldsymbol{\beta}+\mathbf{Z}_{\mathrm{A}-\text { female }} \mathbf{a}_{\text {female }}+\mathbf{Z}_{\mathrm{A} \text {-male }} \mathbf{a}_{\text {male }}+\mathbf{Z}_{\mathrm{PI} \text {-female }} \mathbf{p} \mathbf{i}_{\text {female }} \\
& +\mathbf{Z}_{\mathrm{PI} \text {-male }} \mathbf{p} \mathbf{i}_{\text {male }}+\mathbf{Z}_{\mathrm{YR}} \mathbf{y r}+\mathbf{r},
\end{aligned}
$$

where $\mathbf{X}$ and $\mathbf{Z}$ denote design matrices relating each observation in $\mathbf{y}$ to the appropriate fixed $(\mathbf{X})$ or $\operatorname{random}(\mathbf{Z})$ effect; $\beta$ is a vector of fixed effects, comprising a model intercept and female and male regression slopes on $f\left(\beta_{f \text {-female }}\right.$

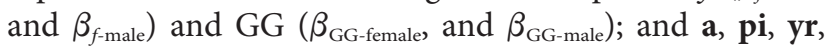
and $\mathbf{r}$ are vectors of random additive genetic, permanent 
individual, year of pair formation, and residual effects, respectively. The variances in $\mathbf{a}, \mathbf{p i}, \mathbf{y r}$, and $\mathbf{r}$ estimated by the animal model are the genetic and nongenetic variance components of interest. A bivariate normal distribution describes female and male additive genetic effects: $\mathbf{a}=$ $\left[\mathbf{a}_{\text {female }}^{\prime}, \mathbf{a}_{\text {male }}^{\prime}\right] \sim \operatorname{BVN}\left([0,0]^{\prime}, \mathbf{G} \otimes \mathbf{A}\right)$, where the prime symbol denotes a vector transpose, $\otimes$ denotes the Kronecker (direct) product, and $\mathbf{A}$ and $\mathbf{G}$ are the numerator relationship matrix (calculated from the pedigree) and the additive genetic covariance matrix:

$$
\mathbf{G}=\left[\begin{array}{cc}
\sigma_{\mathrm{A} \text {-female }}^{2} & \sigma_{\mathrm{A} \text {-female,male }} \\
\sigma_{\mathrm{A} \text {-male,female }} & \sigma_{\mathrm{A} \text {-male }}^{2}
\end{array}\right],
$$

where $\sigma_{\mathrm{A} \text {-female }}^{2}$ and $\sigma_{\mathrm{A} \text {-male }}^{2}$ are the variances in female and male genetic effects and $\sigma_{\mathrm{A} \text {-female,male }}$ is the cross-sex covariance in additive genetic effects (Bijma et al. 2007a, 2007b; Bouwman et al. 2010). $V$ and COV denote empirical variance and covariance estimates, whereas $\sigma^{2}$ and $\sigma$ denote their expectations. Because related females and males share genes, $\sigma_{\mathrm{A} \text {-female,male }}$ represents the covariance in additive genetic effects between a female and all her male relatives weighted by the probability of sharing alleles identical by descent (through A). This is not the covariance in additive genetic effects between a female and her observed socially paired mate (Reid et al. 2014a). Separate univariate normal distributions describe female and male permanent individual effects, year of pair formation effects, and residual effects. Since female and male effects on $k_{\mathrm{SOC}}$ are sex-limited traits, permanent individual effects of females and males are independent and, hence, have a zero covariance (e.g., the permanent individual effect of a male cannot be expressed by a female; Reid et al. 2014a).

In general, unmodeled maternal or paternal environmental effects can inflate estimates of additive genetic variance if they increase the phenotypic resemblance among relatives reared by the same parents (Kruuk 2004). However, the 264 females and 274 males included in our data set had 215 and 211 unique social dams and sires (app. A), respectively, meaning that few individuals whose $k_{\mathrm{SOC}}$ was observed shared common maternal or paternal environments. Estimated $V_{\text {A-female, }} V_{\text {A-male, }}$ and $\mathrm{COV}_{\text {A-female,male }}$ are therefore unlikely to be inflated by parental environmental effects (Kruuk and Hadfield 2007), and supplemental analyses confirmed this expectation (app. A).

\section{Genetic Groups}

Animal models assume that the defined pedigree base population has a mean breeding value of 0 . All unknown parents of individuals in the pedigree (i.e., phantom par- ents; Westell and Van Vleck 1987) are assigned to the base population by default. If two or more groups of individuals within the default base population have different expected mean breeding values, then animal model estimates can be biased (Van Vleck 1990; Hadfield et al. 2010). Selection, immigration, and incomplete parentage data can all cause groups of individuals with different expected mean breeding values to be assigned to the base population (e.g., founder residents versus subsequent immigrants from populations experiencing different selective regimes); therefore, genetic group effects should be modeled to account for the difference in mean breeding value (Westell et al. 1988; Van Vleck 1990).

We demonstrate a general implementation of a genetic group animal model (eq. [1]) by fitting a fixed regression on the contribution of each genetic group to each individual's genome $(\mathbf{Q g})$ in addition to the standard $\mathbf{A}^{-1}$ relationship matrix (Quaas 1988). The matrix Q specifies the fractional contributions from each of $r$ genetic groups to each individual's genome, calculated from pedigree data (Quaas 1988). Q is the first $r$ columns of the $\mathbf{T}$ matrix in Henderson's (1976) decomposition of the numerator relationship $\mathbf{A}=$ TDT $^{\prime}$, where $\mathbf{A}$ includes phantom parents that represent different genetic groups (Robinson 1986; Mrode 2005, chap. 2 and sect. 3.5). The vector $\mathbf{g}$ contains the estimates of the mean breeding values in the base population for each genetic group, expressed as contrasts to a specified reference group mean (here the resident founder group). Thus, for individual $i$ the total additive genetic effect of its genes $\left(u_{i}\right)$ is estimated as the sum of the genetic group means weighted by the contribution of each $r$ genetic group to individual $i$, and the breeding value $\left(a_{i}\right)$ describing the deviation of $i$ from the population mean in the reference genetic group (i.e., 0):

$$
\hat{u}_{\iota}=\sum_{r=1}^{g} q_{i r} \hat{g}_{r}+\hat{a}_{i},
$$

or, in matrix notation (Westell and Van Vleck 1987; Quaas 1988),

$$
\hat{u}=Q \hat{g}+\hat{a} \text {. }
$$

In general, the vectors $\mathbf{u}$ and $\mathbf{a}$ are assumed to have normal distributions with different expected means but the same expected variance: $\mathbf{u} \sim \mathrm{N}\left(\mathbf{Q g}, \sigma_{\mathrm{A}}^{2} \mathbf{A}\right)$ and $\mathbf{a} \sim \mathrm{N}\left(\mathbf{0}, \sigma_{A}^{2} \mathbf{A}\right)$ (Quaas 1988). Therefore, an animal model with fixed effects of genetic groups (eq. [1]) yields an estimate of $\sigma_{A}^{2}$ that is the expected variance in breeding values (a) for all individuals in the base population.

We assigned phantom parents in the song sparrow pedigree to two defined genetic groups: all immigrants were assigned phantom parents from the immigrant genetic group, while all other individuals with two unknown parents were 
assigned phantom parents from the resident genetic group. Since we defined two genetic groups and the genetic group contributions for each individual (rows of $\mathbf{Q}$ ) always sum to 1 , we set the resident genetic group as a reference and estimated the deviation for the immigrant group mean (Quaas 1988). We wrote a function to calculate genetic group contributions $\mathbf{Q}$ (the ggcontrib function in the nadiv $\mathrm{R}$ package, ver. 2.13; Wolak 2012; R Development Core Team 2013) and thereby fitted sex-specific regressions of $k_{\mathrm{SOC}}$ on immigrant GG contributions.

\section{Analysis Implementation}

Residual maximum likelihood was used to estimate fixed effects and random-effect (co)variances using the $\mathrm{R}$ package ASReml-R (ver. 3.0; Butler et al. 2009). Fixed-effect estimates were tested against a null hypothesis of 0 using incremental Wald tests. We performed statistical hypothesis tests of (co)variance components using likelihood ratio tests. The ratio of the likelihood of the full model to the likelihood of a model in which the variance component of interest has been dropped (or fixed at a predetermined value) is an asymptotically $\chi^{2}$ distributed test statistic with degrees of freedom equal to the difference in estimated variance components between the two models (Self and Liang 1987). When testing the hypothesis that a variance differed from 0 , we assumed that the distribution of the likelihood ratio test statistic was a mixture of $\chi^{2}$ distributions with 0 and $1 \mathrm{df}$ (Dominicus et al. 2006) and halved the $P$ value obtained from a $\chi^{2}$ distribution with $1 \mathrm{df}$ (e.g., Careau et al. 2013). When testing the hypothesis that $V_{\mathrm{A} \text {-female }}$ or $V_{\mathrm{A} \text {-male }}$ equaled 0, we fixed a sex-specific genetic variance and the cross-sex genetic covariance to effectively $0(1.0 \times$ $\left.10^{-8}\right)$. This prevented estimation of $\mathrm{COV}_{\mathrm{A} \text {-female,male }}$ when genetic variance was fixed to 0 in one sex. We validated the degrees of freedom used for the $\chi^{2}$ distributions by simulating empirical distributions of the likelihood ratio test statistics (app. A).

In addition to the basic (co)variance estimates, we report the total additive genetic variance $\left(V_{\mathrm{A} \text {-тот }}=V_{\mathrm{A} \text {-female }}+\right.$ $\left.V_{\mathrm{A} \text {-male }}+2 \times \mathrm{COV}_{\mathrm{A} \text {-female,male }}\right)$ and the total phenotypic variance $\left(V_{\mathrm{P}}\right.$; approximated as $V_{\mathrm{P}}=V_{\mathrm{A} \text {-тот }}+V_{\text {PI-female }}+$ $V_{\mathrm{PI} \text {-male }}+V_{\mathrm{YR}}+V_{\mathrm{R}}$; app. A). For comparative purposes, we also report the ratio of total additive to phenotypic variance $\left(V_{\mathrm{A} \text {-тот }} / V_{\mathrm{P}}\right)$; the coefficient of total additive genetic variance $\left(\mathrm{CV}_{\mathrm{A} \text {-TOт }}=\left(V_{\mathrm{A} \text {-TOT }}\right)^{1 / 2} / \bar{X}\right.$, where $\bar{X}$ is the raw phenotypic mean of $k_{\mathrm{SOC}}$; Houle 1992); and the cross-sex additive genetic correlation $\left(r_{\mathrm{A} \text {-female,male }}\right)$. The ratio $V_{\mathrm{A}-\mathrm{TOT}} / V_{\mathrm{P}}$ summarizes the amount of heritable variance available for a response to selection (Bouwman et al. 2010) but is not a heritability as strictly defined (Bijma 2011, 2014; app. A).

We measured uncertainty in model parameter estimates and functions of parameter estimates by sampling the as- ymptotic, multivariate normal distribution of the model parameters following Meyer and Houle (2013) and Houle and Meyer (2015; app. A). To achieve this, we refitted the model (eq. [1]) in WOMBAT (Meyer 2007; estimates were quantitatively similar to ASReml-R estimates; table A1; tables A1-A5, B1 are available online) and used the sample option to obtain 10,000 values of the model parameters simulated from a multivariate normal distribution with mean equal to the maximum likelihood parameter estimates and covariance matrix equal to the covariances of variance parameters obtained from the inverse of the average information matrix (Meyer and Houle 2013). Ratios and sums of variance parameters $\left(V_{\mathrm{A} \text {-female }} / V_{\mathrm{P}}, V_{\mathrm{A} \text {-male }} / V_{\mathrm{P}}\right.$, $\left.V_{\mathrm{A} \text {-тот }}, \mathrm{CV}_{\mathrm{A} \text {-тот }}, V_{\mathrm{P}}, V_{\mathrm{A} \text {-тот }} / V_{\mathrm{P}}, r_{\mathrm{A} \text {-female,male }}\right)$ were also calculated for each sample. Upper and lower limits of the $95 \%$ quantile were defined as the 9,750th and 250th values when samples were sorted in decreasing order.

Pedigrees were pruned to individuals whose $k_{\text {soc }}$ was observed and their known ancestors, and $k_{\text {soc }}$ and $f$ were calculated using standard algorithms implemented in the R package nadiv (Wolak 2012). All $k_{\text {soc }}$ values were multiplied by $10^{3}$ to improve model convergence, and the (co)variances were back transformed by multiplying by $\left(10^{-3}\right)^{2}$. Model residuals did not indicate major violations of linear mixed model assumptions, and conclusions remained similar when models were fitted to raw data and when $k_{\text {soc }}$ was transformed to better approximate a Gaussian response distribution (app. B).

We ran additional analyses to validate our model framework and check for bias. Estimated additive genetic (co)variances remained qualitatively similar when fixed regressions on $f$ and/or GG were excluded from the full model (app. A). We also estimated $V_{\mathrm{A} \text {-female }}$ and $V_{\mathrm{A} \text {-male }}$ in separate, sex-specific univariate animal models considering $k_{\mathrm{SOC}}$ as either a female or a male trait, thereby confirming that the magnitude of female and male additive genetic variances would support interpretation of an estimated $\mathrm{COV}_{\mathrm{A} \text {-female,male }}$ (app. A). Finally, to test whether estimates of $V_{\mathrm{A} \text {-female }}$ and $V_{\mathrm{A} \text {-male }}$ in $k_{\mathrm{SOC}}$ might be inflated by the animal model structure or inherent kinship structure, we used de novo simulations to validate our approach of modeling $k_{\mathrm{SOC}}$ as an emergent trait while exploring the influence of demographic variation on estimates of $V_{\mathrm{A} \text {-female, }} V_{\mathrm{A} \text {-male, }}$ and $\mathrm{COV}_{\mathrm{A} \text {-female,male }}$ (supplementary material B). Data and code for all analyses are deposited in the Dryad Digital Repository: http://dx .doi.org/10.5061/dryad.70ng4 (Wolak and Reid 2016).

\section{Results}

Pedigree, Kinship, and Immigrants

We estimated $k_{\mathrm{soc}}$ for 470 unique socially persistent pairs of song sparrows that bred during 1991-2014. These pair- 
ings were composed of 264 individual females and 274 individual males. Individual females and males formed means of 1.8 (median: 1.0 ; range: $1-6$ ) and 1.7 (median: 1.0 ; range: $1-8$ ) different pairs, respectively. Thirteen $(4.9 \%)$ of the 264 females and 5 (1.8\%) of the 274 males were immigrants.

Mean $k_{\text {SOC }}$ was 0.083 (SD: 0.057; median: 0.074; range: $0.000-0.360$ ), and the distribution was slightly right skewed (skew: 1.56; fig. 1A). Mean $f$ across the 264 females that formed the social pairings was 0.061 (SD: 0.045 ; median: 0.060 ; range: $0.000-0.210$ ) and 0.060 (SD: 0.042 ; median:
0.059; range: $0.000-0.260$ ) across the 274 males (fig. $1 C$ ). The mean contributions of the immigrant genetic group were 0.55 (SD: 0.18 ; median: 0.54 ; range: $0.14-1.00$ ) to the females and 0.53 (SD: 0.16; median: 0.55; range: $0.17-$ 1.00 ) to the males (fig. 1D). Therefore, on average just over half of an individual's genome was derived from immigrant ancestors. The pedigree pruned to the 538 focal individuals, and all their known ancestors contained 720 individuals, including 27 individuals from the resident founder population and 28 subsequent immigrants. The phenotyped indi-
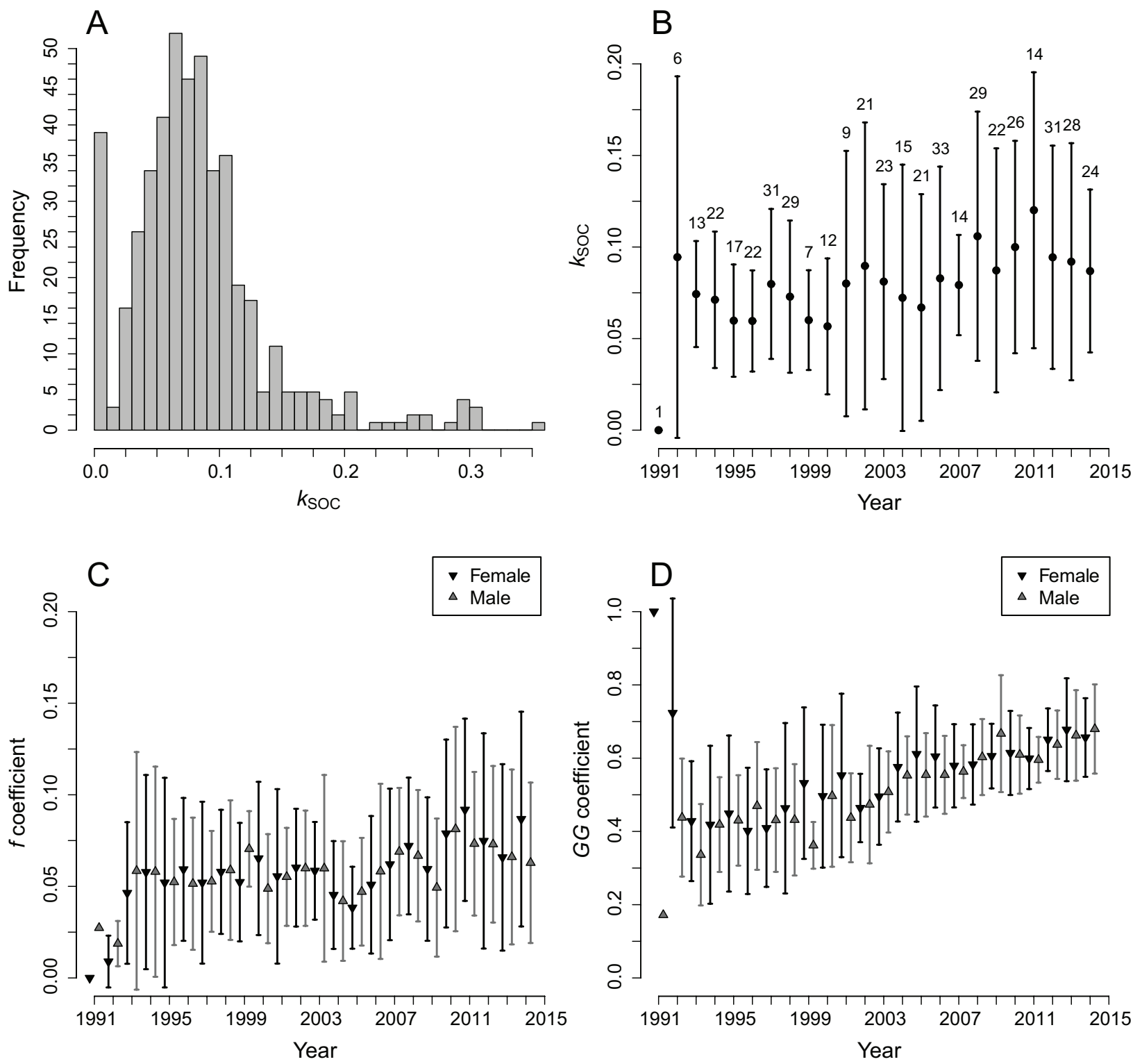

Figure 1: Coefficient of kinship $\left(k_{\mathrm{SoC}}\right)$ between socially paired female and male song sparrows as a frequency histogram across all years $(A)$ and annual means $( \pm 1 \mathrm{SD} ; B)$ and the annual female and male coefficient of inbreeding $(f ; C)$ and genetic group $(\mathrm{GG} ; D)$ contribution from immigrants. Numbers in $B$ give the sample size of $k_{\mathrm{soc}}$ estimates assigned to each year (i.e., the number of new social pairings that formed in that year). In $B-D$, standard deviations are not shown for 1991 because only one social pair contributed to the analysis. 
viduals had substantial pedigree depth and variance in estimated kinship (app. B).

\section{Animal Model}

The univariate animal model estimated appreciable $V_{\text {A-female, }}$ $V_{\mathrm{A} \text {-male, }}$ and $\mathrm{COV}_{\mathrm{A} \text {-femalemale, }}$ based on the random female and male effects (table 1; fig. 2A-2C). Furthermore, a model in which all additive genetic (co)variances were constrained to 0 provided a substantially worse fit to the data ( $\log$ likelihood ratio test: $\chi_{3}^{2}=33.7, P \ll .0001$ ), and none of the lower bounds of the $95 \%$ quantile of the sampling distributions for the additive genetic (co)variance parameters converged to 0 (fig. $2 A-2 C$ ). Therefore, females and males both contributed to the total additive genetic variance in $k_{\text {SOC }}\left(V_{\mathrm{A}-\mathrm{TOT}} ;\right.$ table 1$)$. The full model also fitted the data better than either of two separate reduced models that constrained $V_{\text {A-female }}\left(\chi_{2}^{2}=19.5, P \ll .0001\right)$ or $V_{\text {A-male }}\left(\chi_{2}^{2}=\right.$ $26.3, P \ll .0001)$ to equal 0 . The full model was not significantly different from a model in which $V_{\text {A-female }}$ and $V_{\mathrm{A} \text {-male }}$ were constrained to be equal $\left(\chi_{2}^{2}=0.002, P=.999\right.$; app. A). Female and male contributions to $V_{\text {A-тот }}$ in $k_{\mathrm{SOC}}$ therefore did not differ significantly from one another.

The estimated cross-sex genetic covariance $\left(\mathrm{COV}_{\mathrm{A} \text {-female,male }}\right)$ for $k_{\mathrm{SOC}}$ was significantly greater than $0\left(\chi_{1}^{2}=16.4, P \ll\right.$ .0001 ), and the lower bound of the $95 \%$ quantile of the sampling distribution was greater than 0 (fig. $2 B$ ). Scaling the covariance by $V_{\mathrm{A} \text {-female }}$ and $V_{\mathrm{A} \text {-male }}$ gave a genetic correlation $\left(r_{\mathrm{A} \text {-female,male }}\right)$ of essentially 1 (table 1$)$ with the sampling distribution of the correlation converging to 1 (fig. $2 E$ ), implying that all of the genetic variance for $k_{\mathrm{SOC}}$ is shared between the sexes. $V_{\text {PI-female, }}, V_{\mathrm{PI}-m a l e}$, and $V_{\mathrm{YR}}$ were estimated as effectively 0 (table 1 ). Indeed, there was little power to estimate $V_{\mathrm{PI}}$, since the median number of observations per individual was 1 for both sexes. However, this data structure means that repeated observations of individuals cannot substantially inflate estimates of $V_{\mathrm{A} \text {-female }}$ and $V_{\mathrm{A} \text {-male }}$. The estimate of $V_{\mathrm{YR}} \approx 0$ reflects the low among-year variance observed in $k_{\mathrm{sOC}}$ (fig. $1 B$ ).

The magnitudes of estimated $V_{\text {A-female }}$ and $V_{\text {A-male }}$ along with the strong positive $\mathrm{COV}_{\text {A-female,male }}$ meant that $V_{\mathrm{A} \text {-TOT }}$ was large $\left(V_{\text {A-тот }}=117.9\right.$; table 1$)$. This suggests that there is substantial potential for $k_{\mathrm{soc}}$ to respond to selection. We cannot directly test whether $V_{\mathrm{A} \text {-тот }}$ differs significantly from 0 using a log-likelihood ratio test. However, a heuristic assessment shows that the lower bound on the 95\% quantile of the sampling distribution was greater than 0 (fig. $2 G$ ). Similarly, the two standardized estimates of $V_{\mathrm{A} \text {-тот }}$ ( $V_{\mathrm{A} \text {-тот }} /$ $V_{\mathrm{P}}=0.36$ and $\mathrm{CV}_{\text {A-тот }}=0.42$; table 1 ) both have lower bounds on the $95 \%$ quantile of their sampling distributions that were greater than 0 (fig. $2 \mathrm{H}, 2 \mathrm{I}$ ).

The sex-specific fixed regressions on $f$ showed that the extent to which a female or male was itself inbred had pos- itive effects on $k_{\text {SOC }}$ (table 2). The $f$ regression slope was similar in females and males, although it was significantly greater than 0 for males $\left(\beta_{f \text { male }}=0.16, P=.016\right)$ but marginally nonsignificant in females $\left(\beta_{\text {ffemale }}=0.13, P=\right.$ .057). Therefore, more inbred males - and to some degree females - were more closely related to their socially paired mates, consistent with previously documented phenotypic correlations (Reid et al. 2006; supplementary material A). The sex-specific fixed regressions on GG showed that, as expected, immigrant genes significantly decreased mean $k_{\text {soc }}$ (table 2). Thus, individuals with greater genomic contributions from immigrant ancestors were less closely related to their socially paired mates.

Although the estimated magnitudes of $\beta_{\mathrm{GG}}$ were smaller than the estimated magnitudes of $\beta_{f}$ (table 2), GG contributions caused larger deviations from the population mean $k_{\mathrm{soc}}$ than $f$. For example, the effects of the average GG coefficient on $k_{\mathrm{SOC}}$ (e.g., $\beta_{\mathrm{GG}}$ multiplied by the average GG coefficient) were -0.032 for females and -0.031 for males $(33 \%$ and $31 \%$ decreases from the model intercept of 0.099 , respectively). In comparison, the effects of the average $f$ on $k_{\text {soc }}$ were 0.0080 for females and 0.0093 for males ( $8 \%$ and $9 \%$ increases from the model intercept, respectively).

Sex-specific models that treated $k_{\mathrm{SOC}}$ as either a female trait or a male trait estimated appreciable $V_{\text {A-female }}$ and $V_{\mathrm{A} \text {-male, }}$ yielding results that were qualitatively similar to those of the emergent trait model (app. A). These sexspecific models support the interpretation of the full model analyses, that $V_{\mathrm{A} \text {-female }}$ and $V_{\mathrm{A} \text {-male }}$ do not differ significantly from one another. Simulations showed that nonzero estimates of $V_{\mathrm{A} \text {-TOT }}$ in $k_{\mathrm{SOC}}$ do not arise when our model structure is fitted to simulated data where true $V_{\mathrm{A}}$ is 0 , with or without variation in family size, demonstrating that our estimated $V_{\mathrm{A}} \mathrm{s}$ in song sparrows are not simply artifacts of model structure (supplementary material B).

\section{Discussion}

The pervasive assumption that the degree to which individuals inbreed through any form of mating will evolve in response to selection (Lande and Schemske 1985; Keller and Waller 2002; Szulkin et al. 2013) requires additive genetic variance $\left(V_{\mathrm{A}}\right)$ in the degree of inbreeding expressed through that form of mating. However, neither the magnitude of sex-specific $V_{\mathrm{A}}$ in the degree of biparental inbreeding nor the cross-sex genetic covariance have previously been estimated. We specified a model that enables estimation of total additive genetic variance $\left(V_{\mathrm{A} \text {-тот }}\right)$ for the degree of inbreeding, while explicitly accounting for inbreeding depression and genetic effects of immigrants, and fitted this model to data from free-living song sparrows. We estimated substantial $V_{\mathrm{A} \text {-ToT }}$ in the coefficient of kinship 


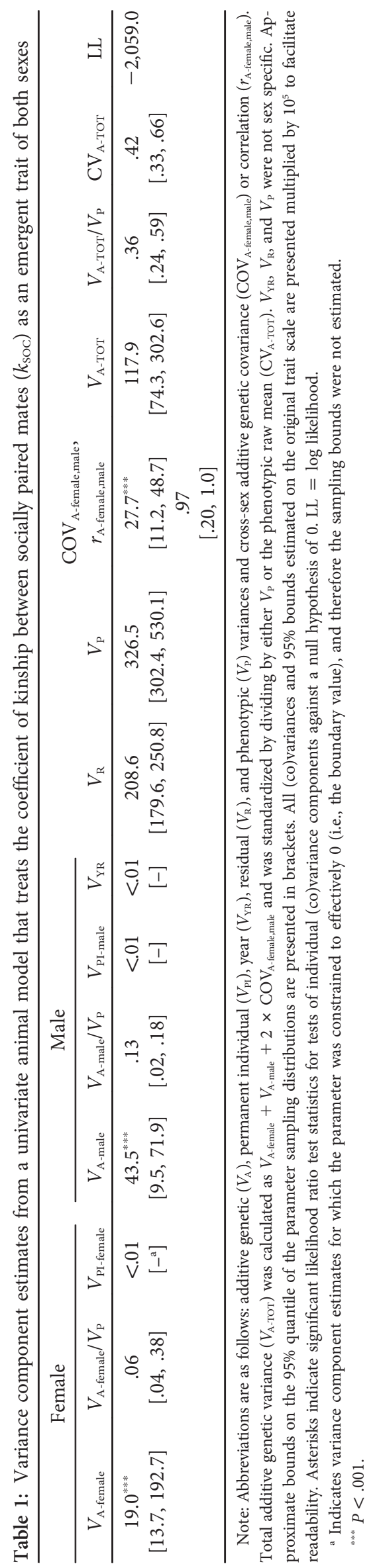

This content downloaded from 139.133.148.027 on May 16, 2016 03:03:13 AM 

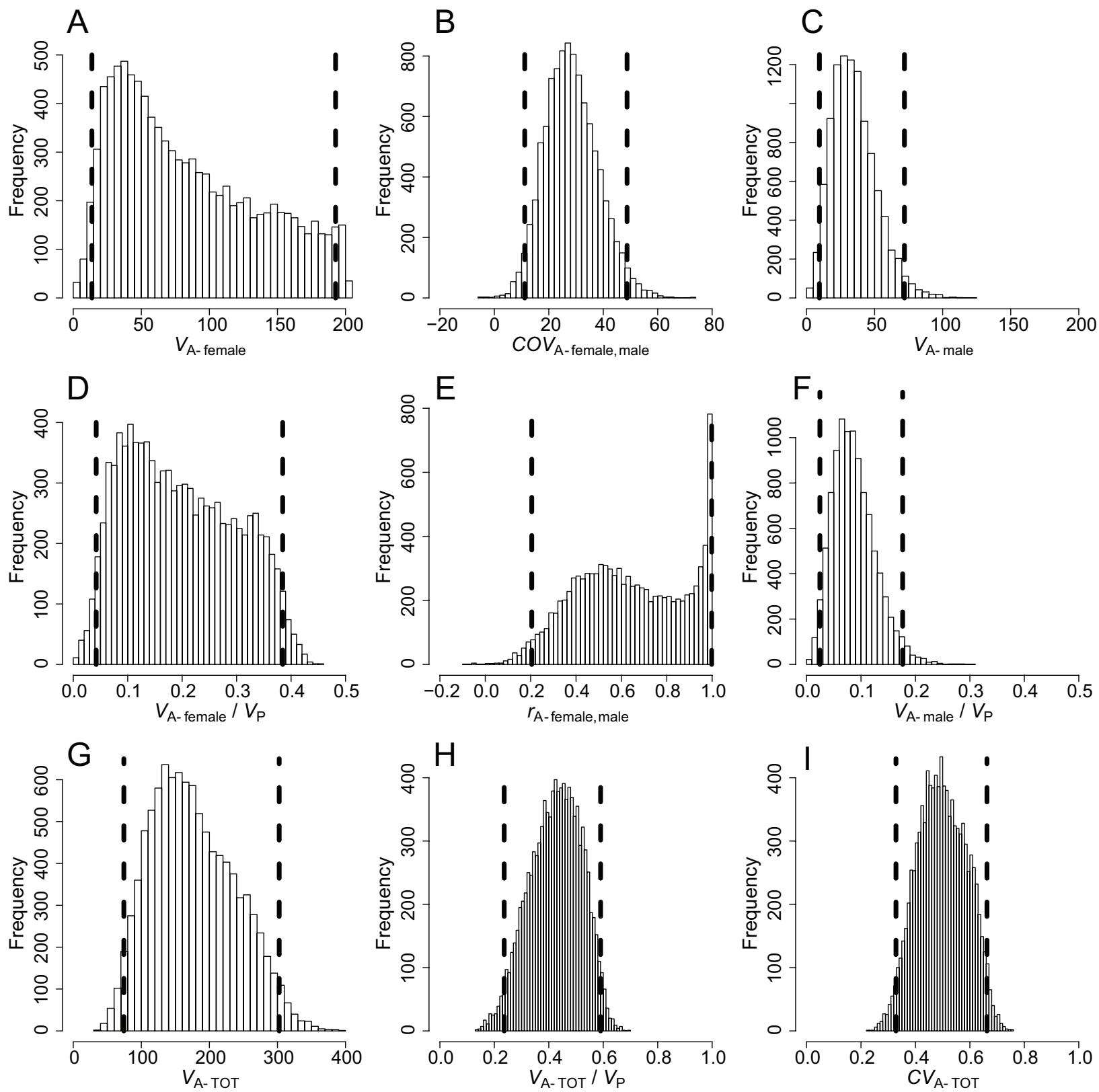

Figure 2: Sampling distributions of modeled female additive genetic variance $(A)$, cross-sex additive genetic covariance $(B)$, male additive genetic variance $(C)$ and the calculated ratio of female additive genetic variance to total phenotypic variance $(D)$, cross-sex additive genetic correlation $(E)$, ratio of male additive genetic variance to total phenotypic variance $(F)$, total additive genetic variance $(G)$, ratio of total additive genetic variance to total phenotypic variance $(H)$, and ratio of the square root of total additive genetic variance to the mean phenotype $(I)$. Vertical dashed lines indicate the lower and upper bounds to the $95 \%$ quantile of the distributions. All (co)variances and $95 \%$ bounds estimated on the original trait scale are presented multiplied by $10^{5}$ to facilitate readability.

between socially paired mates $\left(k_{\mathrm{Soc}}\right)$ stemming from appreciable female and male additive genetic variances $\left(V_{\mathrm{A} \text {-female }}\right.$ and $\left.V_{\mathrm{A} \text {-male }}\right)$ and a positive cross-sex additive genetic covariance $\left(\mathrm{COV}_{\mathrm{A} \text {-female,male }}\right)$. Furthermore, individual inbreeding coefficient $(f)$ and genetic group contribution (GG) affected $k_{\mathrm{SOC}}$, such that individuals that were more inbred or had smaller genomic contributions derived from immigrant ancestors were more closely related to their socially paired mates. Overall, our results suggest that substantial additive genetic variance underlies the degree of biparental 
Table 2: Fixed-effect estimates from a univariate animal model that treats the coefficient of kinship between socially paired mates $\left(k_{\mathrm{SOC}}\right)$ as an emergent trait of both sexes

\begin{tabular}{|c|c|c|c|c|c|c|c|c|c|c|c|c|c|c|}
\hline & & & \multicolumn{6}{|c|}{ Female } & \multicolumn{6}{|c|}{ Male } \\
\hline \multicolumn{3}{|c|}{ Intercept } & \multicolumn{3}{|c|}{$\beta_{f}$} & \multicolumn{3}{|c|}{$\beta_{\mathrm{GG}}$} & \multicolumn{3}{|c|}{$\beta_{f}$} & \multicolumn{3}{|c|}{$\beta_{\mathrm{GG}}$} \\
\hline $\begin{array}{c}\text { Estimate } \\
\text { (SE) }\end{array}$ & $W$ & $P$ & $\begin{array}{c}\text { Estimate } \\
\text { (SE) }\end{array}$ & $W$ & $P$ & $\begin{array}{c}\text { Estimate } \\
\text { (SE) }\end{array}$ & $W$ & $P$ & $\begin{array}{c}\text { Estimate } \\
\text { (SE) }\end{array}$ & $W$ & $P$ & $\begin{array}{c}\text { Estimate } \\
\text { (SE) }\end{array}$ & $W$ & $P$ \\
\hline $\begin{array}{l}.099 \\
(.03)\end{array}$ & 5.63 & .018 & $\begin{array}{c}.13 \\
(.07)\end{array}$ & 3.61 & .057 & $\begin{array}{l}-.06 \\
(.02)\end{array}$ & 18.6 & $<.001$ & $\begin{array}{c}.16 \\
(.07)\end{array}$ & 5.78 & .016 & $\begin{array}{l}-.06 \\
(.03)\end{array}$ & 4.11 & .043 \\
\hline
\end{tabular}

Note: Sex-specific regression slopes $(\beta)$ are presented for the individual coefficient of inbreeding $(f)$ and the contribution of the immigrant genetic group to each individual's genome (GG). Wald statistics $(W)$ are asymptotically $\chi^{2}$ distributed with $1 \mathrm{df}$. SE $=$ standard error.

inbreeding expressed through formation of socially persistent breeding pairs, implying that the degree of such inbreeding could potentially evolve in response to selection.

\section{Additive Genetic (Co)variance in $\mathrm{k}_{\mathrm{SOC}}$}

Evolutionary biologists have only recently begun to simultaneously estimate female and male effects in quantitative genetic analyses of emergent traits associated with mating (Brommer and Rattiste 2008; Teplitsky et al. 2010; Hall et al. 2013; Edward et al. 2014; Reid et al. 2014a). Such emergent trait models fully parameterize the key additive genetic (co)variances that describe the evolutionary potential of a single phenotype that is jointly expressed by paired individuals, identify in which sex (if not both) genetic variance exists and could mediate an evolutionary response to selection (e.g., Hall et al. 2013), and indicate the potential for sexual conflict. Our results imply that both sexes have genetic effects on the degree of inbreeding expressed through social pairing. Although the full emergent trait model estimated $V_{\mathrm{A} \text {-male }}$ to be greater than $V_{\mathrm{A} \text {-female }}$, this difference was not statistically significant. This could simply reflect low statistical power, as suggested by the relatively wide 95\% quantile of the sampling distribution associated with $V_{\mathrm{A} \text {-female }}$ (see app. A). However, models that assigned variation in $k_{\mathrm{SOC}}$ entirely to one sex or the other estimated relatively similar $V_{\mathrm{A}}$ for females and males.

Although no previous studies have estimated $V_{\mathrm{A}}$ in the degree of biparental inbreeding, substantial $V_{\mathrm{A}}$ has been demonstrated in selfing and self-fertility rates in plants (e.g., Carr and Fenster 1994; Good-Avila and Stephenson 2002) and selfing avoidance in plants and hermaphroditic snails (e.g., Holtsford and Ellstrand 1992; Kelly and Arathi 2003; Tsitrone et al. 2003; Escobar et al. 2007, 2009; Herlihy and Eckert 2007; Bartkowska and Johnston 2009). Genetic variation has also been estimated in morphological traits that affect selfing, such as the physical separation of anthers and stigmas within flowers (herkogamy; e.g., Motten and Stone 2000; Herlihy and Eckert 2007). Multitrait composite interval mapping (Fishman et al. 2002) also suggests that selfing in yellow monkeyflowers (Mimulus nasutus) has evolved through directional selection on many genes of relatively small effect (Lin and Ritland 1997), providing evidence for a polygenic basis to selfing. However, since all of these studies focus on genetic variation in the rate of selfing versus outcrossing rather than in biparental inbreeding, cross-sex genetic covariances in inbreeding - and, hence, the potential for sexual conflict over inbreeding - have not been quantified.

Although a paired female and male share the same degree of inbreeding $\left(k_{\mathrm{SOC}}\right)$, the fitness consequences of that inbreeding may still be sex specific (Pizzari et al. 2004; Parker 2006; Duthie and Reid 2015). Determining the potential for or amount of sexual conflict over biparental inbreeding necessitates estimation of $V_{\mathrm{A} \text {-female, }} V_{\mathrm{A} \text {-male, }}$ and $\mathrm{COV}_{\mathrm{A} \text {-female,male }}$ as well as sex-specific selection on inbreeding (e.g., Reid et al. 2015a). Our estimate of a large and positive $\mathrm{COV}_{\text {A-female,male }}$ in song sparrows suggests that most genetic variation for the degree of inbreeding expressed through social pairing is closely associated between females and males. $\mathrm{COV}_{\mathrm{A} \text {-female,male }}$ was estimated with substantial uncertainty, manifested as a wide $95 \%$ quantile of the sampling distribution, as is frequently the case for cross-sex genetic covariances (Poissant et al. 2010). However, both the lower bound of the sampling distribution and the log-likelihood ratio tests suggest that $\mathrm{COV}_{\mathrm{A} \text {-female,male }}$ was significantly greater than 0 . Furthermore, estimates of $\mathrm{COV}_{\mathrm{A} \text {-female,male }}$ from all supplemental models differing in random-effect structures remained broadly consistent, supporting our conclusion that the cross-sex genetic covariance for the degree to which individuals inbreed through social pairing is positive (see app. A).

At present, there is no formal theory that predicts the direction or magnitude of $\mathrm{COV}_{\mathrm{A} \text {-female,male }}$ in the degree of biparental inbreeding that might be expected to exist or arise. Some loci common to both sexes might underlie the female and male genetic contributions to $k_{\mathrm{SOC}}$ resulting in pleiotropy that could cause a positive cross-sex covariance. Any such positive covariance might then be reinforced by linkage disequilibria that accumulate due to the assortative 
reproduction that seems inevitable if female and male relatives tend to carry alleles that promote inbreeding and consequently pair with each other. However, theory suggests that any sexual conflict over the optimal degree of inbreeding stemming from opposing genetic covariances between the degree of inbreeding and sex-specific fitness might act against such assortative mating. New theory is therefore needed to predict the evolutionary dynamics of $\mathrm{COV}_{\mathrm{A} \text {-female,male given }}$ different scenarios of sex-specific selection on the degree of biparental inbreeding that incorporates possible feedbacks between the evolution of $V_{\mathrm{A} \text {-female, }} V_{\mathrm{A} \text {-male, }}$ and $\mathrm{COV}_{\mathrm{A} \text {-female,male }}$ and the degree of inbreeding.

\section{Evolutionary Prediction}

In general, the potential for an evolutionary response to selection on an emergent trait is described by the variance in total breeding value ( $V_{\mathrm{A}-\mathrm{TOT}}$; Bijma et al. $2007 a$; Bijma 2014). Given our estimate of substantial $V_{\mathrm{A} \text {-тот }}$ in the degree to which song sparrows inbreed by forming socially persistent breeding pairs with relatives, it might seem tempting to measure selection on such inbreeding and combine these parameters to quantitatively predict evolutionary change in the mating system. However, measuring sex-specific selection on inbreeding in a wild population is challenging, requiring the consequences of any degree of inbreeding for female and male fitness to be quantified (Reid et al. 2008, 2015a). Predicting evolutionary change in any trait in the wild is also challenging (e.g., Merilä et al. 2001; Morrissey et al. 2010), and the occurrence of inbreeding further complicates variance partitioning and evolutionary predictions.

First, quantitative genetic equations predicting responses to selection change when genetic dominance and inbreeding are present because dominance (co)variance components contribute to the selection response (Harris 1964; Jacquard 1974, pp. 131-138; Shaw et al. 1998; Kelly and Arathi 2003; Wolak and Keller 2014). However, formulations of quantitative genetic models for emergent traits have been restricted to two (i.e., additive and dominance; Griffing 1967) of the five genetic (co)variance components necessary to predict evolutionary change in these cases. Therefore, quantitative genetic theory concerning evolutionary changes in emergent traits when inbreeding and dominance effects are present needs to be extended before quantitative prediction of evolutionary change in the degree of inbreeding can be attempted.

Second, the total phenotypic variance $\left(V_{\mathrm{P}-\mathrm{TOT}}\right)$ is required to parameterize existing equations that predict evolutionary responses in emergent traits (Bijma et al. 2007a; Ellen et al. 2007; Bouwman et al. 2010; Bijma 2011, 2014). Estimating $V_{\text {Р-тот }}$ for emergent traits in general requires multiplying the covariance in breeding values between all group members (e.g., in our case, a paired female and male) by the mean relatedness (defined as a correlation of homologous alleles between individuals; Wright 1921) within groups to account for correlation in breeding values due to kinship (e.g., Bouwman et al. 2010; app. A) However, assortative mating with respect to kinship will introduce covariance between mates in breeding values for inbreeding in addition to the covariance expected from shared ancestry. It is unclear how to model this additional covariance and, hence, how to estimate $V_{\text {P-тот. }}$ Existing equations predicting evolutionary responses to selection on emergent traits therefore cannot be directly parameterized when kinship is the focal trait.

Finally, $V_{\text {А-тот, }}$ as defined by existing quantitative genetic theory, quantifies the potential for evolutionary change assuming the form of selection on the emergent trait is the same across all population members. For emergent traits resulting from mating, this requires that the cross-sex additive genetic covariance in the emergent trait has the same sign as the cross-sex additive genetic covariance in fitness and, hence, that selection acts in the same direction on both sexes. However, sexual conflict over mating is widely observed (Arnqvist and Rowe 2005), and selection on biparental inbreeding is widely expected to differ between females and males (e.g., Kokko and Ots 2006; Parker 2006; Duthie and Reid 2015). Consequently, predicting evolutionary change in emergent traits of mates requires quantifying direct selection on each sex and indirect selection through the opposite sex in addition to estimating $V_{\mathrm{A} \text {-female, }}$ $V_{\mathrm{A}-m a l e}$, and $\mathrm{COV}_{\mathrm{A} \text {-female,male }}$ (Moore and Pizzari 2005). Expressions predicting evolutionary change in emergent traits therefore need to be extended to allow for divergent selection on interacting females and males, as has been done for traits considered to be expressed by one sex (Brommer et al. 2007). In summary, our estimate of nonzero $V_{\mathrm{A}-\text { тот }}$ in song sparrows demonstrates the potential for evolutionary change in the degree of inbreeding expressed through social pairing, but quantitative prediction of such change cannot yet be attempted.

\section{Inbreeding and Immigration}

The positive regression coefficients of $k_{\mathrm{SOC}}$ on female and male $f$ indicate that more inbred individuals were more closely related to their socially paired mates. These relationships can be interpreted as inbreeding depression in the degree of inbreeding (i.e., increased inbreeding by more inbred individuals) and suggest that directional dominance contributes to variation in the degree of inbreeding expressed through social pairing. Although the combination of inbreeding and directional dominance alters trait means and variances (Falconer and Mackay 1996, chap. 14; Lynch and Walsh 1998, chap. 10), inbreeding depression in 
the degree of inbreeding is estimated in an animal model through the regression on $f$ and the diagonal elements of the A matrix (Kennedy and Sorensen 1988; Wolak and Keller 2014). Consequently, effects attributed to the $f$ coefficients are separated from the additive genetic effects underlying the degree of inbreeding, allowing unbiased estimation of $V_{\mathrm{A}}$ from the random female and male effects associated with the pedigree.

Inbreeding depression in the degree of inbreeding might reflect inbreeding depression in individual ability to discriminate kin or arise because mate choice is more constrained and correlated among inbred individuals (Reid et al. 2006, 2008; see also "Mechanisms and Consequences" and supplementary material A). Inbred relatives might share constraints on mate choice if there is inbreeding depression in attractiveness, competitiveness, or timing of breeding. One prediction is therefore that there should be inbreeding depression in inbreeding avoidance, defined as a negative deviation from the degree of inbreeding expected given random mating (Szulkin et al. 2013). There is some evidence of such inbreeding depression in Mandarte's song sparrows (Reid et al. 2006). In contrast, inbreeding was not observed to affect traits that influence the occurrence of selfing in Mimulus guttatus (e.g., herkogamy; Kelly and Arathi 2003).

The joint existence of $V_{\mathrm{A}}$ and inbreeding depression in the degree of inbreeding implies that different families may be more likely to experience inbreeding with further consequences for mating system evolution. Among-family variation in inbreeding $\left(V_{\mathrm{A}}\right)$ might eventually lead to localized purging of deleterious recessives, causing amongfamily variation in inbreeding depression (Kelly 2005). Indeed, such variation is a key component of theoretical models linking the evolution of selfing to inbreeding depression (e.g., Campbell 1986; Holsinger 1988). However, there is currently no equivalent theory relating amongfamily variance in inbreeding depression to the evolution of biparental inbreeding; such theory could usefully be developed.

We directly quantified the association between $k_{\text {SOC }}$ and the expected proportion of an individual's genome that was derived from immigrants by fitting sex-specific regressions on genetic group contributions. We estimated a negative mean genetic difference for the expression of $k_{\mathrm{SOC}}$ in immigrants compared with residents. Specifically, our model predicts $k_{\mathrm{SOC}}=0.085$ between an average female song sparrow with all resident ancestors and an average male and $k_{\mathrm{SOC}}=0.056$ between an average female with one immigrant parent and an average male (a $34 \%$ reduction).

The estimated genetic group effect quantifies the genetic effect of among-deme dispersal on the degree of inbreeding but does not quantify genetic effects on dispersal itself or quantify the effect of immigration on any nonrandom mate choice following dispersal. Interestingly, the GG coefficients showed that, despite the relatively low rate of immigration to Mandarte, approximately half an average phenotyped song sparrow's genome has originated from immigrants. This implies that, per capita, immigrants may make relatively substantial genetic contributions to the population (e.g., Marr et al. 2002) compared with the defined resident group. More generally, our genetic group regressions demonstrate that it is relatively straightforward to explicitly incorporate the additive genetic effects of immigrants into animal models. Genetic effects of other individuals with unknown parents that might differ genetically from the true pedigree base population (e.g., individuals in subsequent generations whose parents were not observed) could be modeled in an analogous way, thereby eliminating biases that could otherwise arise in estimates of $V_{\mathrm{A}}$ (e.g., Hadfield et al. 2010).

\section{Mechanisms and Consequences}

Our estimate of $V_{\mathrm{A} \text {-тот }}$ in $k_{\mathrm{SOC}}$ raises the question of how such variation might arise in terms of behavioral and/or demographic mechanisms that underlie inbreeding. The pattern of inbreeding arising through social pairing depends on the expression of mate choice (Jennions and Petrie 1997; Cotton et al. 2006) and on the structure and distribution of kinship among individuals at the time of pairing (Reid et al. 2006). Such kinship structure will vary with population size, immigration rate, sex ratio, social structure, and variance in reproductive success and, hence, family or lineage size (Jacquard 1974, pp. 197-201; Nunney 1993; Falconer and Mackay 1996, p. 68; Reid and Keller 2010; Reid et al. 2015c). Specifically, variance in family size creates among-individual variation in the degree of inbreeding that would be expressed given random pairing (Jacquard 1974, pp. 197-201; Reid et al. 2006; Reid and Keller 2010). This is because the probability of inbreeding is greater for individuals with many relatives in the population than for individuals with fewer relatives (Jacquard 1974, pp. 197-201; van Noordwijk and Scharloo 1981; Reid and Keller 2010). A phenotypic covariance between fitness and the degree of inbreeding could therefore arise even if pairing is random with respect to kinship. Nonzero $V_{\mathrm{A}}$ in $k_{\text {SOC }}$ might then be an inevitable consequence of $V_{\mathrm{A}}$ in fitness. However, our null simulations suggest that $V_{\mathrm{A}}$ in fitness (e.g., family size) alone is not sufficient to create detectable $V_{\mathrm{A} \text {-тот }}$ in $k_{\text {SOC }}$ such as that observed in Mandarte's song sparrows (supplementary material B).

Fine-scale temporal, spatial, or social structure in the distribution of kinship among individuals available for pairing could also create variance in $k_{\mathrm{SOC}}$ given random pairing among available individuals. For example, relatives 
may have similar reproductive timing, social status, or habitat selection, whether due to shared developmental, genetic, maternal, or common environmental causes (Reid et al. 2008; Szulkin and Sheldon 2008; Robinson et al. 2012; Reid et al. $2015 c$ ); $V_{\mathrm{A} \text {-тот }}$ in $k_{\mathrm{SOC}}$ could then arise if family resemblance in reproductive timing covaried with fitness. For example, on Mandarte male song sparrows that hatch earlier within their cohort are more closely related to the set of available females and pair with more closely related females than expected given random pairing. Furthermore, individuals that hatch earlier have more relatives in the population because early breeders have higher reproductive success (Arcese 1989; Smith et al. 2006; Wilson et al. 2007). Relatives might also be nonrandomly distributed in space (e.g., Foerster et al. 2006), and so random pairing among relatively proximate individuals may be a passive mechanism leading to family resemblance and, hence, $V_{\mathrm{A} \text {-тот }}$ in $k_{\text {SOC. }}$. However, there is no detectable spatial structure in kinship in song sparrows within Mandarte (Arcese 1989; Reid et al. 2015b).

Alternatively or additionally, $V_{\mathrm{A} \text {-тот }}$ in $k_{\mathrm{SOC}}$ could reflect additive genetic variance in inbreeding strategy, defined as nonrandom pairing with respect to kinship (Szulkin et al. 2013). Such nonrandom pairing would in turn require some mechanism by which individuals could discriminate among kin. In general, kin discrimination could be enacted through a direct molecular mechanism (e.g., Penn and Potts 1999; Zelano and Edwards 2002). Previous analyses highlighted an additional mechanism by which Mandarte's song sparrows could potentially adjust $k_{\mathrm{soc}}$. Male song repertoire size, a secondary sexual trait, shows inbreeding depression and therefore indicates a male's own $f$ (Reid et al. 2005). Meanwhile, a male's own $f$ is positively correlated with his mean kinship with the female population (Reid et al. 2006). A directional preference for males with large song repertoire size would therefore allow females to acquire relatively unrelated mates and, hence, to produce relatively outbred offspring on average (Reid 2007). $V_{\mathrm{A}}$ in female preference could therefore potentially create $V_{\mathrm{A}}$ in $k_{\mathrm{SOC}}$. The next step toward elucidating the mechanistic basis of $V_{\mathrm{A}}$ in the degree of inbreeding expressed through social pairing will be to disentangle sources of variation arising from kinship structure versus inbreeding strategy, which will in turn require population-wide variation in inbreeding strategy to be measured and decomposed into genetic and nongenetic sources.

\section{Acknowledgments}

We thank the Tsawout and Tseycum First Nation bands for access to Mandarte, P. Arcese and everyone who contributed to the long-term data collection, and the European Research Council and Royal Society for funding. We thank
P. Bijma, J. D. Hadfield, L. F. Keller, and E. Postma for illuminating discussions. In addition, R. Bonduriansky, L. E. B. Kruuk, and an anonymous reviewer provided insightful comments that improved the manuscript.

\section{Literature Cited}

Ala-Honkola, O., M. K. Manier, S. Lüpold, and S. Pitnick. 2011. No evidence for postcopulatory inbreeding avoidance in Drosophila melanogaster. Evolution 65:2699-2705.

Ala-Honkola, O., A. Uddström, B. D. Pauli, and K. Lindström. 2009. Strong inbreeding depression in male mating behaviour in a poeciliid fish. Journal of Evolutionary Biology 22:1396-1406.

Arcese, P. 1989. Intrasexual competition, mating system and natal dispersal in song sparrows. Animal Behaviour 38:958-979.

Arcese, P., M. K. Sogge, A. B. Marr, and M. A. Patten. 2002. Song sparrow (Melospiza melodia). A. Poole, ed. Birds of North America online. Cornell Laboratory of Ornithology, Ithaca, NY. Accessed March 19, 2015. http://bna.birds.cornell.edu/bna/species/704.

Arnqvist, G., and L. Rowe. 2005. Sexual conflict. Princeton University Press, Princeton, NJ.

Aspi, J. 2000. Inbreeding and outbreeding depression in male courtship song characters in Drosophila montana. Heredity 84:273282.

Baker, H. G. 1955. Self-compatibility and establishment after "longdistance" dispersal. Evolution 9:347-349.

Bartkowska, M. P., and M. O. Johnston. 2009. Quantitative genetic variation in populations of Amsinckia spectabilis that differ in rate of self-fertilization. Evolution 63:1103-1117.

Bijma, P. 2011. A general definition of the heritable variation that determines the potential of a population to respond to selection. Genetics 189:1347-1359.

. 2014. The quantitative genetics of indirect genetic effects: a selective review of modelling issues. Heredity 112:61-69.

Bijma, P., W. M. Muir, E. D. Ellen, J. B. Wolf, and J. A. M. van Arendonk. 2007a. Multilevel selection 2: estimating the genetic parameters determining inheritance and response to selection. Genetics 175:289-299.

Bijma, P., W. M. Muir, and J. A. M. van Arendonk. 2007b. Multilevel selection 1: quantitative genetics of inheritance and response to selection. Genetics 175:277-288.

Billing, A. M., A. M. Lee, S. Skjelseth, A. A. Borg, M. C. Hale, J. Slate, H. Pärn, et al. 2012. Evidence of inbreeding depression but not inbreeding avoidance in a natural house sparrow population. Molecular Ecology 21:1487-1499.

Boake, C. R. B. 1989. Repeatability: its role in evolutionary studies of mating behavior. Evolutionary Ecology 3:173-182.

Bolund, E., K. Martin, B. Kempenaers, and W. Forstmeier. 2010. Inbreeding depression of sexually selected traits and attractiveness in the zebra finch. Animal Behaviour 79:947-955.

Bouwman, A. C., R. Bergsma, N. Duijvesteijn, and P. Bijma. 2010. Maternal and social genetic effects on average daily gain of piglets from birth until weaning. Iournal of Animal Science 88:28832892.

Brommer, J. E., M. Kirkpatrick, A. Qvarnström, and L. Gustafsson. 2007. The intersexual genetic correlation for lifetime fitness in the wild and its implications for sexual selection. PLoS ONE 2: e744. 
Brommer, J. E., and K. Rattiste. 2008. "Hidden" reproductive conflict between mates in a wild bird population. Evolution 62:2326-2333.

Butler, D. G., B. R. Cullis, A. R. Gilmour, and B. J. Gogel. 2009. asreml: asreml() fits the linear mixed model. R package version 3.0. http://www.vsni.co.uk.

Campbell, R. B. 1986. The interdependence of mating structure and inbreeding depression. Theoretical Population Biology 30:232-244.

Careau, V., M. E. Wolak, P. A. Carter, and T. J. Garland. 2013. Limits to behavioral evolution: the quantitative genetics of a complex trait under directional selection. Evolution 67:3102-3119.

Carr, D. E., and C. B. Fenster. 1994. Levels of genetic variation and covariation for Mimulus (Scrophulariaceae) floral traits. Heredity 72:606-618.

Cavalli-Sforza, L. L., M. Kimura, and I. Barrai. 1966. The probability of consanguineous marriages. Genetics 54:37-60.

Charlesworth, D. 2006. Evolution of plant breeding systems. Current Biology 16:R726-R735.

Charlesworth, D., and B. Charlesworth. 1987. Inbreeding depression and its evolutionary consequences. Annual Review of Ecology and Systematics 18:237-268.

Charmantier, A., D. Garant, and L. E. B. Kruuk, eds. 2014. Quantitative genetics in the wild. Oxford University Press, Oxford.

Cotton, S., J. Small, and A. Pomiankowski. 2006. Sexual selection and condition-dependent mate preferences. Current Biology 16 R755-R765.

Crnokrak, P., and S. C. H. Barrett. 2002. Purging the genetic load: a review of the experimental evidence. Evolution 56:2347-2358.

Crow, J. F. 1970. Genetic loads and the cost of natural selection. Pages 128-177 in K. I. Kokima, ed. Mathematical topics in population genetics. Springer, Berlin.

Darwin, C. R. 1876. The effects of cross and self fertilization in the vegetable kingdom. J. Murray, London.

de Boer, I. J. M., and J. A. M. van Arendonk. 1992. Prediction of additive and dominance effects in selected or unselected populations with inbreeding. Theoretical and Applied Genetics 84:451-459.

Dominicus, A., A. Skrondal, H. K. Gjessing, N. L. Pedersen, and J. Palmgren. 2006. Likelihood ratio tests in behavioral genetics: problems and solutions. Behavior Genetics 36:331-340.

Duthie, A. B., and J. M. Reid. 2015. What happens after inbreeding avoidance? inbreeding by rejected relatives and the inclusive fitness benefit of inbreeding avoidance. PloS ONE 10:e0125140.

Edward, D. A., J. Poissant, A. J. Wilson, and T. Chapman. 2014. Sexual conflict and interacting phenotypes: a quantitative genetic analysis of fecundity and copula duration in Drosophila melanogaster. Evolution 68:1651-1660.

Ellen, E. D., W. M. Muir, F. Teuscher, and P. Bijma. 2007. Genetic improvement of traits affected by interactions among individuals: sib selection schemes. Genetics 176:489-499.

Escobar, J. S., G. Epinat, V. Sarda, and P. David. 2007. No correlation between inbreeding depression and delayed selfing in the freshwater snail Physa acuta. Evolution 61:2655-2670.

Escobar, J. S., B. Facon, P. Jarne, J. Goudet, and P. David. 2009. Correlated evolution of mating strategy and inbreeding depression within and among populations of the hermaphroditic snail Physa acuta. Evolution 63:2790-2804.

Falconer, D. S., and T. Mackay. 1996. Introduction to quantitative genetics. 4th ed. Longman, Harlow.

Fishman, L., A. J. Kelly, and J. H. Willis. 2002. Minor quantitative trait loci underlie floral traits associated with mating system divergence in Mimulus. Evolution 56:2138-2155.
Foerster, K., M. Valcu, A. Johnsen, and B. Kempenaers. 2006. A spatial genetic structure and effects of relatedness on mate choice in a wild bird population. Molecular Ecology 15:4555-4567.

Fuller, J. L., and M. E. Hahn. 1976. Issues in the genetics of social behavior. Behavior Genetics 6:391-406.

Good-Avila, S. V, and A. G. Stephenson. 2002. The inheritance of modifiers conferring self-fertility in the partially self-incompatible perennial, Campanula rapunculoides L. (Campanulaceae). Evolution 56:263-272.

Goodwillie, C., S. Kalisz, and C. G. Eckert. 2005. The evolutionary enigma of mixed mating systems in plants: occurrence, theoretical explanations, and empirical evidence. Annual Review of Ecology Evolution, and Systematics 36:47-79.

Greenwood, P. J., and P. H. Harvey. 1982. Dispersal of birds. Annual Review of Ecology and Systematics 13:1-21.

Griffing, B. 1967. Selection in reference to biological groups. I. Individual and group selection applied to populations of unordered groups. Australian Journal of Biological Sciences 20:127-139.

Hadfield, J. D., A. J. Wilson, D. Garant, B. C. Sheldon, and L. E. B. Kruuk. 2010. The misuse of BLUP in ecology and evolution. American Naturalist 175:116-125.

Hall, M. D., S. P. Lailvaux, and R. C. Brooks. 2013. Sex-specific evolutionary potential of pre- and postcopulatory reproductive interactions in the field cricket, Teleogryllus commodus. Evolution 67: 1831-1837.

Harris, D. L. 1964. Genotypic covariances between inbred relatives. Genetics 50:1319-1348.

Henderson, C. R. 1973. Sire evaluation and genetic trends. Journal of Animal Science 1973:10-41.

- 1976. A simple method for computing the inverse of a numerator relationship matrix used in prediction of breeding values. Biometrics 32:69-83.

Herlihy, C. R., and C. G. Eckert. 2007. Evolutionary analysis of a key floral trait in Aquilegia canadensis (Ranunculaceae): genetic variation in herkogamy and its effect on the mating system. Evolution 61:1661-1674.

Holsinger, K. E. 1988. Inbreeding depression doesn't matter: the genetic basis of mating-system evolution. Evolution 42:1235-1244.

Holtsford, T. P., and N. C. Ellstrand. 1992. Genetic and environmental variation in floral traits affecting outcrossing rate in Clarkia tembloriensis (Onagraceae). Evolution 46:216-225.

Houle, D. 1992. Comparing evolvability and variability of quantitative traits. Genetics 130:195-204.

Houle, D., and K. Meyer. 2015. Estimating sampling error of evolutionary statistics based on genetic covariance matrices using maximum likelihood. Journal of Evolutionary Biology 28:1542-1549.

Jacquard, A. 1974. The genetic structure of populations. Springer, Berlin.

Jamieson, I. G., S. S. Taylor, L. N. Tracy, H. Kokko, and D. P. Armstrong. 2009. Why some species of birds do not avoid inbreeding: insights from New Zealand robins and saddlebacks. Behavioral Ecology 20:575-584.

Janssen, M. H., P. Arcese, M. S. Sloan, and K. J. Jewell. 2008. Polyandry and sex ratio in the song sparrow. Wilson Journal of Ornithology 120:395-398.

Jennions, M. D., and M. Petrie. 1997. Variation in mate choice and mating preferences: a review of causes and consequences. Biological Reviews 72:283-327.

Keller, L. F. 1998. Inbreeding and its fitness effects in an insular population of song sparrows (Melospiza melodia). Evolution 52:240-250. 
Keller, L. F., and P. Arcese. 1998. No evidence for inbreeding avoidance in a natural population of song sparrows (Melospiza melodia). American Naturalist 152:380-392.

Keller, L. F., K. J. Jeffery, P. Arcese, M. A. Beaumont, W. M. Hochachka, J. N. M. Smith, and M. W. Bruford. 2001. Immigration and the ephemerality of a natural population bottleneck: evidence from molecular markers. Proceedings of the Roval Societv B: Biological Sciences 268:1387-1394.

Keller, L. F., and D. M. Waller. 2002. Inbreeding effects in wild populations. Trends in Ecology and Evolution 17:19-23.

Kelly, J. K. 2005. Family level inbreeding depression and the evolution of plant mating systems. New Phytologist 165:55-62.

Kelly, J. K., and H. S. Arathi. 2003. Inbreeding and the genetic variance in floral traits of Mimulus guttatus. Heredity 90:77-83.

Kennedy, B. W., L. R. Schaeffer, and D. A. Sorensen. 1988. Genetic properties of animal models. Journal of Dairy Science 71:17-26.

Kokko, H., M. D. Jennions, and R. Brooks. 2006. Unifying and testing models of sexual selection. Annual Review of Ecology, Evolution, and Systematics 37:43-66.

Kokko, H., and I. Ots. 2006. When not to avoid inbreeding. Evolution 60:467-475.

Kruuk, L. E. B. 2004. Estimating genetic parameters in natural populations using the "animal model." Philosophical Transactions of the Roval Societv B: Biological Sciences 359:873-890.

Kruuk, L. E. B., and J. D. Hadfield. 2007. How to separate genetic and environmental causes of similarity between relatives. Journal of Evolutionary Biology 20:1890-1903.

Lande, R., and D. W. Schemske. 1985. The evolution of selffertilization and inbreeding depression in plants. I. Genetic models. Evolution 39:24-40.

Lebigre, C., P. Arcese, R. J. Sardell, L. F. Keller, and J. M. Reid. 2012. Extra-pair paternity and the variance in male fitness in song sparrows (Melospiza melodia). Evolution 66:3111-3129.

Lehmann, L., and N. Perrin. 2003. Inbreeding avoidance through kin recognition: choosy females boost male dispersal. American Naturalist 162:638-652.

Lin, J. Z., and K. Ritland. 1997. Quantitative trait loci differentiating the outbreeding Mimulus guttatus from the inbreeding M. platycalyx. Genetics 146:1115-1121.

Lloyd, D. G. 1979. Some reproductive factors affecting the selection of self-fertilization in plants. American Naturalist 113:67-79.

Losdat, S., S.-M. Chang, and J. M. Reid. 2014. Inbreeding depression in male gametic performance. Journal of Evolutionary Biology 27:992-1011.

Lynch, M., and B. Walsh. 1998. Genetics and analysis of quantitative traits. Sinauer, Sunderland, MA.

Marr, A. B., L. F. Keller, and P. Arcese. 2002. Heterosis and outbreeding depression in descendants of natural immigrants to an inbred population of song sparrows (Melospiza melodia). Evolution 56:131-142.

Merilä, J., B. C. Sheldon, and L. E. B. Kruuk. 2001. Explaining stasis: microevolutionary studies in natural populations. Genetica 112 113:199-222.

Meyer, K. 2007. WOMBAT - a tool for mixed model analyses in quantitative genetics by restricted maximum likelihood (REML). Lournal of Zheiiang University Science B 8:815-821.

Meyer, K., and D. Houle. 2013. Sampling based approximation of confidence intervals for functions of genetic covariance matrices. Proceedings of the Association for the Advancement of Animal Breeding and Genetics 20:523-526.
Moore, A. J., E. D. Brodie III, and J. B. Wolf. 1997. Interacting phenotypes and the evolutionary process. I. Direct and indirect genetic effects of social interactions. Evolution 51:1352-1362.

Moore, A. J., and T. Pizzari. 2005. Quantitative genetic models of sexual conflict based on interacting phenotypes. American Naturalist 165:S88-S97.

Moore, J., and R. Ali. 1984. Are dispersal and inbreeding avoidance related? Animal Behaviour 32:94-112.

Morrissey, M. B., L. E. B. Kruuk, and A. J. Wilson. 2010. The danger of applying the breeder's equation in observational studies of natural populations. Journal of Evolutionary Biology 23:2277-2288.

Motten, A. F., and J. C. Stone. 2000. Heritability of stigma position and the effect of stigma-anther separation on outcrossing in a predominantly self-fertilizing weed, Datura stramonium (Solanaceae). American Journal of Botany 87:339-347.

Mrode, R. A. 2005. Linear models for the prediction of animal breeding values. 2nd ed. CABI, Cambridge, MA.

Nietlisbach, P., G. Camenisch, T. Bucher, J. Slate, L. F. Keller, and E. Postma. 2015. A microsatellite-based linkage map for song sparrows (Melospiza melodia). Molecular Ecology Resources 15:1486-1496.

Nunney, L. 1993. The influence of mating system and overlapping generations on effective population size. Evolution 47:1329-1341.

Parker, G. A. 2006. Sexual conflict over mating and fertilization: an overview. Philosophical Transactions of the Roval Society B: Biological Sciences 361:235-259.

Penn, D. J., and W. K. Potts. 1999. The evolution of mating preferences and major histocompatibility complex genes. American Naturalist 153:145-164.

Pizzari, T., H. Løvlie, and C. K. Cornwallis. 2004. Sex-specific, counteracting responses to inbreeding in a bird. Proceedings of the Roval Societv B: Biological Sciences 271:2115-2121.

Poissant, J., A. J. Wilson, and D. W. Coltman. 2010. Sex-specific genetic variance and the evolution of sexual dimorphism: a systematic review of cross-sex genetic correlations. Evolution 64:97-107.

Postma, E. 2006. Implications of the difference between true and predicted breeding values for the study of natural selection and micro-evolution. Journal of Evolutionary Biology 19:309-320.

Pusey, A., and M. Wolf. 1996. Inbreeding avoidance in animals. Trends in Ecology and Evolution 11:201-206.

Quaas, R. L. 1988. Additive genetic model with groups and relationships. Journal of Dairy Science 71:1338-1345.

R Core Team. 2013. R: a language and environment for statistical computing. R Foundation for Statistical Computing, Vienna.

Reid, J. M. 2007. Secondary sexual ornamentation and non-additive genetic benefits of female mate choice. Proceedings of the Roval Society B: Biological Sciences 274:1395-1402.

. 2014. Quantitative genetic approaches to understanding sexual selection and mating system evolution in the wild. In A. Charmantier, D. Garant, and L. E. B. Kruuk, eds. Quantitative genetics in the wild. Oxford University Press, Oxford.

Reid, J. M., P. Arcese, G. Bocedi, A. B. Duthie, M. E. Wolak, and L. F. Keller. 2015a. Resolving the conundrum of inbreeding depression but no inbreeding avoidance: estimating sex-specific selection on inbreeding by song sparrows (Melospiza melodia). Evolution 69: 2846-2861.

Reid, J. M., P. Arcese, A. L. E. V. Cassidy, A. B. Marr, J. N. M. Smith, and L. F. Keller. 2005. Hamilton and Zuk meet heterozygosity? song repertoire size indicates inbreeding and immunity in song sparrows (Melospiza melodia). Proceedings of the Roval Society B: Biological Sciences 272:481-487. 
Reid, J. M., P. Arcese, and L. F. Keller. 2006. Intrinsic parentoffspring correlation in inbreeding level in a song sparrow ( $\mathrm{Mel}$ ospiza melodia) population open to immigration. American Naturalist 168:1-13.

. 2008. Individual phenotype, kinship, and the occurrence of inbreeding in song sparrows. Evolution 62:887-899.

Reid, J. M., P. Arcese, L. F. Keller, R. R. Germain, A. B. Duthie, S. Losdat, M. E. Wolak, et al. 2015b. Quantifying inbreeding avoidance through extra-pair reproduction. Evolution 69:59-74.

Reid, J. M., P. Arcese, L. F. Keller, and S. Losdat. 2014a. Female and male genetic effects on offspring paternity: additive genetic (co)variances in female extra-pair reproduction and male paternity success in song sparrows (Melospiza melodia). Evolution 68: 2357-2370

Reid, J. M., P. Arcese, R. J. Sardell, and L. F. Keller. 2011. Additive genetic variance, heritability, and inbreeding depression in male extrapair reproductive success. American Naturalist 177:177-187.

Reid, J. M., A. B. Duthie, M. E. Wolak, and P. Arcese. 2015c. Demographic mechanisms of inbreeding adjustment through extra-pair reproduction. Iournal of Animal Ecology 84:1029-1040.

Reid, J. M., and L. F. Keller. 2010. Correlated inbreeding among relatives: occurrence, magnitude, and implications. Evolution 64:973-985.

Reid, J. M., L. F. Keller, A. B. Marr, P. Nietlisbach, R. J. Sardell, and P. Arcese. 2014b. Pedigree error due to extra-pair reproduction substantially biases estimates of inbreeding depression. Evolution 68:802-815.

Rioux-Paquette, E., M. Festa-Bianchet, and D. W. Coltman. 2010. No inbreeding avoidance in an isolated population of bighorn sheep. Animal Behaviour 80:865-871.

Robinson, G. K. 1986. Group effects and computing strategies for models for estimating breeding values. Lournal of Dairy Science 69:3106-3111.

Robinson, S. P., W. J. Kennington, and L. W. Simmons. 2012. Assortative mating for relatedness in a large naturally occurring population of Drosophila melanogaster. Journal of Evolutionary Biology 25:716-725.

Sardell, R. J., L. F. Keller, P. Arcese, T. Bucher, and J. M. Reid. 2010. Comprehensive paternity assignment: genotype, spatial location and social status in song sparrows, Melospiza melodia. Molecular Ecology 19:4352-4364.

Self, S. G., and K. Y. Liang. 1987. Asymptotic properties of maximum likelihood estimators and likelihood ratio tests under nonstandard conditions. Iournal of the American Statistical Association 82:605-610.

Shaw, R. G., D. L. Byers, and F. H. Shaw. 1998. Genetic components of variation in Nemophila menziesii undergoing inbreeding: morphology and flowering time. Genetics 150:1649-1661.

Smith, J. N. M., L. F. Keller, A. B. Marr, and P. Arcese, eds. 2006. Conservation and biology of small populations: the song sparrows of Mandarte Island. Oxford University Press, Oxford.

Szulkin, M., and B. C. Sheldon. 2008. Correlates of the occurrence of inbreeding in a wild bird population. Behavioral Ecology 19:12001207.
Szulkin, M., K. V. Stopher, J. M. Pemberton, and J. M. Reid. 2013 Inbreeding avoidance, tolerance, or preference in animals? Trends in Ecology and Evolution 28:205-211.

Templeton, A. R. 1986. Coadaptation and outbreeding depression. Pages 105-116 in M. E. Soule, ed. Conservation biology: the science of scarcity and diversity. Sinauer, Sunderland, MA.

Teplitsky, C., J. A. Mills, J. W. Yarrall, and J. Merilä. 2010. Indirect genetic effects in a sex-limited trait: the case of breeding time in red-billed gulls. Iournal of Evolutionary Biology 23:935-944.

Tsitrone, A., P. Jarne, and P. David. 2003. Delayed selfing and resource reallocations in relation to mate availability in the freshwater snail Physa acuta. American Naturalist 162:474-488.

van Noordwijk, A. J., and W. Scharloo. 1981. Inbreeding in an island population of the great tit. Evolution 35:674-688.

Van Vleck, L. D. 1990. Breeding value prediction with maternal genetic groups. Journal of Animal Science 68:3998-4013.

Waser, P. M., S. N. Austad, and B. Keane. 1986. When should animals tolerate inbreeding? American Naturalist 128:529-537.

Webster, M. S., S. Pruett-Jones, D. F. Westneat, and S. J. Arnold. 1995. Measuring the effects of pairing success, extra-pair copulations and mate quality on the opportunity for sexual selection. Evolution 49:1147-1157.

Westell, R. A., R. L. Quaas, and L. D. Van Vleck. 1988. Genetic groups in an animal model. Journal of Dairy Science 71:13101318.

Westell, R. A., and L. D. Van Vleck. 1987. Simultaneous genetic evaluation of sires and cows for a large population of dairy cattle. Journal of Dairy Science 70:1006-1017.

Wilson, S., D. R. Norris, A. G. Wilson, and P. Arcese. 2007. Breeding experience and population density affect the ability of a songbird to respond to future climate variation. Proceedings of the Roval Society B: Biological Sciences 274:2539-2545.

Wolak, M. E. 2012. nadiv: an R package to create relatedness matrices for estimating non-additive genetic variances in animal models. Methods in Ecology and Evolution 3:792-796.

Wolak, M. E., and L. F. Keller. 2014. Dominance genetic variance and inbreeding in natural populations. Pages 104-127 in A. Charmantier, D. Garant, and L. E. B. Kruuk, eds. Quantitative genetics in the wild. Oxford University Press, Oxford.

Wolak, M. E., and J. M. Reid. 2016. Data from: Is pairing with a relative heritable? estimating female and male genetic contributions to the degree of biparental inbreeding in song sparrows (Melospiza melodia). American Naturalist, Dryad Digital Repository, http://dx.doi.org/10.5061/dryad.70ng4.

Wright, S. 1921. Systems of mating. Genetics 6:111-178.

-1969. Evolution and the genetics of populations: the theory of gene frequencies. Vol. 2. University of Chicago Press, Chicago.

Zelano, B., and S. V. Edwards. 2002. An Mhc component to kin recognition and mate choice in birds: predictions, progress, and prospects. American Naturalist 160:S225-S237.

Associate Editor: Russell Bonduriansky Editor: Susan Kalisz 